\title{
Primary and secondary prevention of cardiovascular disease in patients with hyperlipoproteinemia (a)
}

\author{
P. Grützmacher ${ }^{1}$ B. Öhm ${ }^{1}$ S. Szymczak ${ }^{1}$ C. Dorbath ${ }^{1}$ - M. Brzoska ${ }^{1}$ C. Kleinert ${ }^{1}$
}

Published online: 23 February 2017

(c) The Author(s) 2017. This article is available at SpringerLink with Open Access.

\begin{abstract}
General lipoprotein (Lp) (a) screening can help to identify patients at high risk for cardiovascular disease. Non-invasive methods allow early detection of clinically asymptomatic incipient atherosclerotic disease. Medical treatment options are still unsatisfactory. $\mathrm{Lp}(\mathrm{a})$ apheresis is an established treatment in Germany for secondary prevention of progressive cardiovascular disease. Statin-based lowering of LDL cholesterol and thrombocyte aggregation inhibitors still represent the basis of medical treatment. Target levels for LDL-cholesterol should be modified in patients with hyperlipoproteinemia (a).
\end{abstract}

Keywords Lipoprotein (a) - Lp (a) apheresis · Cardiovascular prevention · Target LDL cholesterol

\section{Introduction}

The role of $\mathrm{Lp}$ (a) as an independent risk factor is meanwhile generally accepted [1-3]. The aim of secondary prevention of cardiovascular and other vascular diseases in patients with hyperlipoproteinemia (a) is to prevent further lethal and non-lethal complications, if an atherosclerotic disease is already clinically manifest. Mostly the coronary arteries, the arteries of the lower extremities and the cerebrovascular system of patients in the second half of life are

This article is part of the special issue " $\mathrm{Lp}(\mathrm{a})$ - the underestimated cardiovascular risk factor'

P. Grützmacher

peter.gruetzmacher@fdk.info

1 2nd Medical Clinic - Nephrology, Hypertension and Vascular Diseases, AGAPLESION Markus-Hospital, Frankfurt/Main, Germany involved. Primary prevention usually focuses on younger patients without clinically symptomatic atherosclerotic disease. Statins have shown to be effective in primary prevention even in patients with intermediate risk [4,5].

The use of non-invasive diagnostic procedures as e.g. B-mode sonography of blood vessels or cardiac computed tomography contributes to early risk stratification. With these techniques a continuous progression of atherosclerotic plaques sometimes can be observed over decades in clinically asymptomatic patients. Therefore primary and secondary prevention are no longer strictly discriminated.

\section{Indication for screening of $\operatorname{Lp}(a)$}

As screening for lipoprotein (Lp) (a) of the general population is currently not yet recommended, many patients miss early preventive strategies. For secondary prevention, $\mathrm{Lp}$ (a) should be measured in premature cardiovascular disease and progressive atherosclerotic disease despite correction of all other risk factors, especially despite optimal lipidlowering treatment. For primary prevention, Lp (a) screening is recommended in patients with a positive family history of premature cardiovascular diseases, elevated Lp (a) in other family members, familial hypercholesterolemia, and in high-risk patients with a 10 -year risk of fatal cardiovascular disease of 5-10\% according to the ESC score [6]. It should be discussed to extend Lp (a) screening to every individual with a vascular event, which can not sufficiently be explained by typical risk factors, independent of the patient's age. Furthermore, a high coincidence with genetically induced hemostatic defects has to be considered [7]. 
Table 1 Drugs with significant effects on serum Lp(a) concentration

\begin{tabular}{|c|c|c|c|}
\hline Substance & Mode of action & Reduction of Lp(a) (\%) & Special notes \\
\hline Nicotinic acid & Classical drug & $20-30$ & Moderate side effects \\
\hline $\begin{array}{l}\text { Evolocumab } \\
\text { Alirocumab }\end{array}$ & PCSK9 antibodies & $15-30$ & Very low side effects \\
\hline Lomitapide & MTP inhibitor & $15-32$ & Risk of steatosis \\
\hline Mipomersen & $\begin{array}{l}\text { Apo B100 antisense oligonu- } \\
\text { cleotide }\end{array}$ & $20-35$ & Risk of steatosis \\
\hline ISIS-APO (a) 144367 & $\begin{array}{l}\text { Apo (a) antisense oilgo- } \\
\text { nucelotide }\end{array}$ & $30-80$ & Clinical trials still running \\
\hline
\end{tabular}

No drug has yet been approved for specific treatment of hyperlipoproteinemia (a)

No effect on clinical endpoints has yet been demonstrated in neither drug

Table 2 Primary and secondary prevention of cardiovascular disease in patients with hyperlipoproteinemia (a). Possible therapeutic strategies

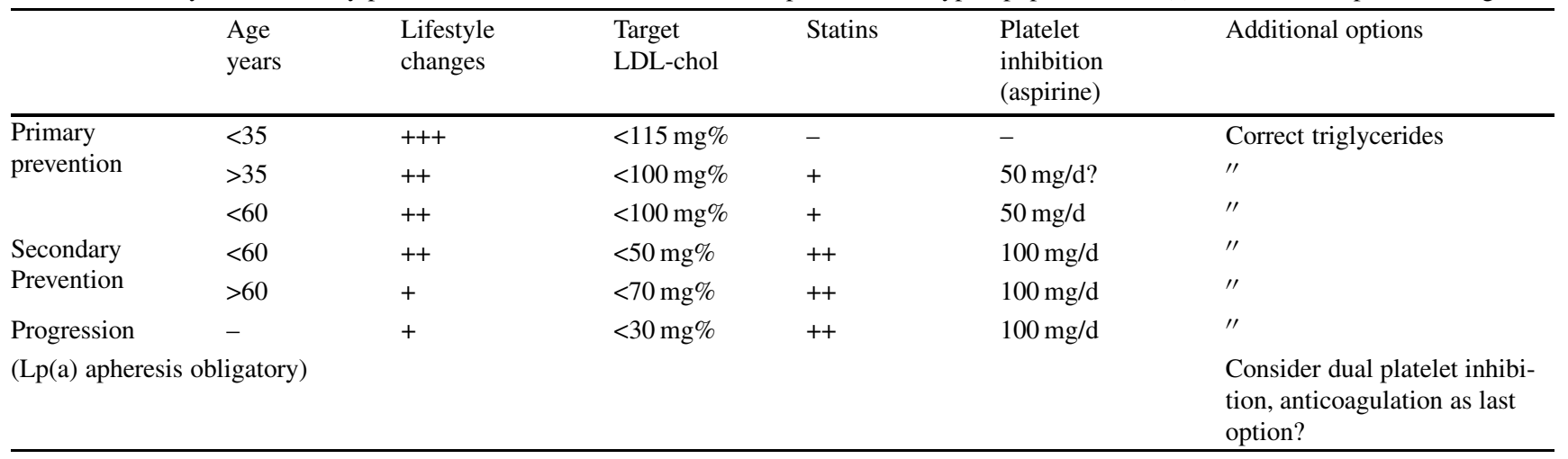

End-stage renal disease and the nephrotic syndrome are most frequent causes of secondary hypolipoproteinemia (a) $[8,9]$.

In many patients, an unexpected cardiovascular event induces the first measurement of $\mathrm{Lp} \mathrm{(a)} \mathrm{and} \mathrm{a} \mathrm{profound}$ evaluation of conventional, generally accepted risk factors; the German lipid league proposes a general screening of the whole population by at least one single measurement in life. As the laboratory methods still have a high variance, 2-3 controls may be indicated, if exact risk estimation is necessary $[9,10]$.

\section{Therapeutic options in hyperlipoproteinemia (a)}

Lifestyle changes and statins have no relevant effects on serum Lp (a) concentrations. Several drugs are able to reduce elevated Lp (a) levels by 5-30\%. However, up to now there is no evidence of any reduction of clinical vascular endpoints for all substances. Neither has any of these drugs been approved by the German authorities for the treatment of hyperlipoproteinemia (a) (Table 1).

Nicotinic acid at a daily dose of $2-3 \mathrm{~g} /$ die can reduce Lp (a) levels by up to $30 \%$. Similar results have been shown for microsomal triglyceride transfer protein inhibitor lomitapide and the apo-B-100 antisense oligonucleotide mipom- ersen. However, both drugs bear a considerable risk of the development of fatty liver disease, being the main reason of failing German drug approval for the treatment of elevated LDL-cholesterol and lipoprotein (a) levels [11-13].

Two PCSK9-antibodies have been introduced for the treatment of severe hypercholesterolemia, refractory to conventional drug combinations. In contrast to their impressive potential on LDL-cholesterol, the influence on Lp (a) is markedly lower; a lowering of Lp (a) levels by up to $30 \%$ has been reported, the reduction rate is below $20 \%$ in patients with high levels of Lp (a) [14, 15].

A most promising approach is the antisense oligonucleotide against apolipoprotein (a), where reduction rates up to $80 \%$ seem possible; nevertheless, the necessary clinical study protocols for drug approval have not yet been completed [16]. Therefore, in daily practice no option for a direct medical correction of hyperlipoproteinemia (a) is available.

In Germany Lp (a) apheresis is an established treatment for patients with elevated $\mathrm{Lp}$ (a) levels providing reduction rates of $60-70 \%$ compared to baseline and pre-apheresis levels. Lp (a) apheresis has been approved for secondary prevention in patients with clinically manifest cardiovascular diseases, which is progressive despite the correction of all other risk factors, and in patients with already extended 
cardiovascular diseases, in whom a progression is assumed to have deleterious consequences [17].

An impressive reduction of cardiovascular complications has been observed in five observation studies in different German patient cohorts [18-23].

The annual quality report of the Kassenärztliche Bundesvereinigung of 2015 included 953 patients with isolated hyperlipoproteinemia (a) treated with regular Lp (a) apheresis [24].

\section{Treatment of hyperlipoproteinemia (a) by individual risk stratification}

Without any effective medical treatment option for lowering $\mathrm{Lp}$ (a)-levels, primary prevention has to focus on on the reduction of the total individual risk for cardiovascular disease and thus on the correction of classical concomitant risk factors which are not discussed here (Table 2).

In young and healthy patients without risk factors, even strongly elevated Lp (a) levels to more than 3.5 fold above normal induce only a small increment of the absolute cardiovascular risk - in spite of doubling the relative risk. However, if other factors such ass smoking, hypertension, male sex, age $>60$ years or classical Framingham risks of $>20 \% / 10$ years are present, a dramatic increment of the absolute risk can been observed [25, 26].

But the risk of elevated Lp (a) level alone is already comparable to the risk of smoking or arterial hypertension in low risk situations, those being classical targets of preventive efforts in daily practice.

Further discrimination of cardiovascular risk is partially possible by the measurement of the genetic variants rs10455872 and 3798220, which determine the serum concentration of $L p$ (a) as well as the size of $L p$ (a) particles by the numbers of kringle IV-type 2 copies [27].

Except for apheresis, specific recommendations for the management of patients with hyperlipoproteinemia (a) have not yet been established. This is explained by the lack of therapeutics options and of clinical evidence of any differentiated medical strategy.

It has been shown that the cardiovascular risk of elevated of LDL cholesterol is considerably increased in the presence of an additionally elevated Lp(a) level (a) [28, 29].

It is the current concept to establish optimal LDL-cholesterol target levels in patients with hyperlipoproteinemia (a) by means of dietary restrictions and the use of statins, although this strategy has not yet been confirmed by clinical endpoint studies [30].

In patients with moderate risk (score risk $1 \leq 5 \%$ ), the current ESC/EAS-guideline of 2016 recommend a target LDL-cholesterol of $<115 \mathrm{mg} \%(<3.0 \mathrm{mmol} / \mathrm{l})$ if at least one classical major risk factor is present (6). Although $\mathrm{Lp}(\mathrm{a})$ is not yet accepted as a major risk factor, this target level should be implemented for patients with elevated $\mathrm{Lp}(\mathrm{a})$ levels.

In patient with a 10 -year risk of $5 \leq 10 \%$, ESC/EASguidelines recommend a LDL target level of $<100 \mathrm{mg} \%$, if at least one further major risk factor is present. It should be remembered that the risk difference of these 2 groups is mainly caused by gender and age.

The use of platelet inhibition is not generally recommended for primary prevention even in elderly persons [40]. As Lp (a) exerts considerable prothrombotic effects [31, 32], a primary protection can be discussed, e. g. using low dose aspirin in adult patients $>35$ years of age. At least in patients $>60$ years, a positive risk/benefit ratio may be expected, if already minor evidence of vessel alterations is present.

In patients with clinically symptomatic atherosclerotic disease, secondary prevention regularly includes the use of platelet inhibitors, usually aspirin at a dose of $100 \mathrm{mg} / \mathrm{die}$ and the use of statins in order to reduce LDL-cholesterol below a target level of $70 \mathrm{mg} \%$ [33-36].

In $\mathrm{Lp}$ (a) patients with premature cardiovascular disease below 60 years of age, a therapeutic target of $<50 \mathrm{mg} \%$ may be regarded as a more safe strategy, and in patients with advanced or progressive cardiovascular disease despite optimal guideline-based therapy, aggressive lowering of LDLcholesterol to $<30 \mathrm{mg} \%$ as well as combined platelet inhibition should be considered, as these regimens hardly bear any clinically relevant risk [37, 38].

Apart from that, the correction of elevated serum triglycerides should further contribute to a reduction of the total cardiovascular risk [39].

In exceptional cases with advanced and recurrent vascular occlusions, triple therapy including anticoagulatory substances as vitamin $\mathrm{K}$ antagonists, thrombin and factor $\mathrm{Xa}$ inhibitors may be advantageous [38, 40].

\section{Conclusion}

In patients with hyperlipidaemia (a) very early identification and comprehensive risk management are mandatory for successful cardiovascular prevention as long as a direct and efficient medical correction is not available and $\mathrm{Lp}(\mathrm{a})$ apheresis is not yet required.

Conflict of interest P. Grützmacher has received honoraria for lectures from Fresenius, B. Braun, Diamed, Kaneka, Amgen, Sanofi and MSD, B. Öhm, S. Szymczak, C. Dorbath, M. Brzoska and C. Kleinert declare that they have no competing interests.

Open Access This article is distributed under the terms of the Creative Commons Attribution 4.0 International License (http:// creativecommons.org/licenses/by/4.0/), which permits unrestricted use, distribution, and reproduction in any medium, provided you give 
appropriate credit to the original author(s) and the source, provide a link to the Creative Commons license, and indicate if changes were made.

\section{References}

1. Ridker P, Hennekens C, Stampfer M (1993) A prospective study of lipoprotein(a) and the risk of myocardial infarction. JAMA 270:2195-2199

2. Emerging Risk Factors Collaboration (2009) Lipoprotein(a) concentration and the risk of coronary heart disease, stroke, and nonvascular mortality. JAMA 303:412-423

3. Nordestgaard B, Chapman M, Ray K et al (2010) Lipoprotein(a) as a cardiovascular risk factor: current status. Eur Heart J 31:2844-2853

4. Yusuf S, Lonn E, Pais P et al (2016) Blood-pressure and cholesterol lowering in persons without cardiovascular disease. N Engl J Med 374:2032-2043

5. Yusuf S, Bosch J, Dagenais G et al (2016) Cholesterol lowering in intermediate-risk persons without cardiovascular disease. N Engl J Med 374:2021-2031

6. Catapano A, Graham I, De Backer G et al (2016) ESC/EAS, guidelines for the management of dyslipidaemias. Eur Heart $\mathrm{J}$ 37:2999-3058. doi:10.1093/eurheartj/ehw272

7. Kostner KM, März W, Kostner GM (2013) When should we measure lipoprotein(a)? Eur Heart J 34:3268-3270

8. Kronenberg F, Utermann G (2013) Lipoprotein(a) resurrected by genetics. J Intern Med 273:6-30

9. Kronenberg F, Lingenhel A, Lhotta K et al (2004) Lipoprotein(a) and low density-derived cholesterol in nephrotic syndrome. Kidney Int 66:348-394

10. Marcovina SM, Albers JJ (2016) Lipoprotein (a) measurement for clinical application. J Lipid Res 57:526-537

11. Cuchel M, Meagher EA, du Toit TH et al (2013) Efficacy and safety of a microsomal triglyceride transfer protein inhibitor. Lancet 381:40-46

12. Crooke ST, Geary RS (2013) Clinical pharmacological properties of mipomersen (Kynamro),a second generation antisense inhibitor of apolipoprotein B. Br J Clin Pharmacol 76:269-276. doi:10.1111/ j.1365-2125.2012.04469.x

13. Santos R, Raal F, Catapano A et al (2015) Mipomersen, an antisense oligonucleotide to apolipoprotein B100, reduces lipoprotein(a) in various populations with hypercholesterolemia. Arterioscler Thromb Vasc Biol 35:689-699. doi:10.1161/atvbaha.114.304549

14. Desai N, Kohili P, Giugliano R et al (2013) AMG145, a monoclonal antibody against PCSK9, significantly reduces lipoprotein(a) in hypercholesterolemic patients receiving statin therapy. Circulation 128:962-969

15. Gaudet D, Gerald F, Watts et al (2017) Effect of alirocumab on lipoprotein(a) over $\geq 1.5$ Years. Am J Cardiol 119:40-46. doi:10. 1016/j.amjcard.2016.09.010

16. Tsimikas S, Viney NJ, Hughes SG et al (2015) Antisense therapy targeting apolipoprotein (a): a randomized, doubleblind placebocontrolled phase I study. Lancet 386:1472-1483

17. Bundesausschuss der Ärzte und Krankenkassen (2013) Richtlinie zu Untersuchungs- und Behandlungsmethoden der vertragsärztlichen Versorgung (MVV-RL) Durchführung der Apheresen als extrakorporales Hämotherapieverfahren. BAnz AT B7:1-3 (08.04.2013)

18. Jaeger BR, Richter Y, Nagel D et al (2009) Longitudinal cohort study on the effectiveness of lipid apheresis treatment to reduce high lipoprotein(a) levels and prevent major adverse coronary events. Nat Clin Pract Cardiovasc Med 6:229-239

19. For the Pro(a)Life-study group, Leebmann J, Röseler E, Julius U et al (2013) Lipoprotein apheresis in patients with maximally tol- erated lipid lowering therapy, Lp(a)-hyperlipoproteinemia and progressive cardiovascular disease - a prospective observational multicenter study. Circulation 128:2567-2567

20. Rosada A, Kassner U, Vogt A et al (2014) Does regular lipid apheresis in patients with isolated elevated lipoprotein(a) levels reduce the incidence of cardiovascular events? Artif Organs 38:135-141

21. Von Dryander M, Fischer S, Passauer J et al (2013) Differences in the atherogenic risk of patients treated by lipoprotein apheresis according to their lipid pattern. Atheroscler Suppl 14:39-44

22. Heigl F, Hettich R, Lotz N et al (2015) Efficacy, safety and tolerability of long-term lipoprotein apheresis in patients with LDL- or Lp (a)-hyperlipoproteinamia. Atheroscler Suppl 18:154-163

23. Roeseler E, Julius U, Heigl F et al (2016) Lipoprotein apheresis for lipoprotein(a)-associated cardiovascular disease: prospective 5 years of follow-up and apolipoprotein(a) characterization. Arterioscler Thromb Vasc Biol 36:2019-2202

24. Kassenärztliche Bundesvereinigung (2016) KBV-Qualitätsbericht Ausgabe 2015 Berichtsjahr 2014. www.kbv.de/media/sp/KBV Qualitaetsbericht_2014.pdf

25. Kiechl S, Willeit J, Mayr M et al (2007) Oxydised phospholipids,lipoprotein(a),lipoprotein-associated phospholipase A2 activity and 10-year cardiovascular outcome. Prospective results from the Bruneck study. Arterioscler Thromb Vasc Biol 27:1788-1795

26. Kamstrup P, Benn M, Tybaerg-Hansen A et al (2008) Extreme lipoprotein(a) levels and risk of myocardial inforation in the general population. The Copenhagen City Heart study. Circulation 117:176-184

27. Clarke R, Peden JF, Hopewell JC et al (2009) Procardis consortium. Genetic variants associated with $\mathrm{Lp}$ (a) level and coronary heart disease. N Engl J Med 361:2518-2528

28. Cremer P, Nagel D, Labrot B (1994) Lipoprotein(a) as a predictor of myocardial infarction in comparison to fibrinogen, LDL cholesterol and other risk factors. Results of the Goettingen Incidence and prevalence study (Grips). Eur J Clin Invest 24:444-453

29. Von Eckardstein A, Schulte H, Cullen P, Assmann G (2001) Lipoprotein (a) further increases the risk of coronary events in men with high cardiovascular risk. J Am Coll Cardiol 37:434-439

30. Parhofer K (2007) Schwere Dyslipoproteinämie-Strategien zu Diagnostik und Therapie. UniMed, Bremen. ISBN 978-3895992322

31. Kraft H, Utermann A (2007) Lipoprotein(a). In: Schwandt P, Parhofer K (eds) Handbuch der Fettstoffwechselstörungen. Schattauer, Stuttgart, pp 216-230

32. Sechi LA, Catena C, Casaccio D, Zigaro L (2000) Lipoprotein (a) haemostatic variables and cardiocascular damage in hypertensive patients. J Hypertens 18:709-716

33. Yussuf S (2002) Commentary: two decades of progress in preventing cardiovascular disease. Lancet 360:2-3

34. Alonso-Coello P, Bellmunt S, McGrorian C et al (2012) Antithrombotic therapy in peripheral artery disease: Antithrombotic therapy and prevention of thrombosis, 9th ed: American College of Chest Physicians Evidence-Based Clinical Practice Guidelines. Chest 141:e669-e690

35. S3 Leitlinie _Teil 1:Sekundärprophylaxe ischämischer Schlaganfall und transitorische ischämische Attacke online www.dyn.org/ images/red_leitlinien/LL-2014/pdf-Download/030-133_kurz-S3Sekundärprophylaxe_ischämischer_Schlaganfall_2015-02.pdf

36. Piepoli M, Hoes A, Agewall S et al (2016) European Guidelines on cardiovascular disease prevention in clinical practice. Eur Heart J 37:2315-2381. doi:10.1093/eurheartj/ehw106

37. Zhang XL, Zhu QQ, Zhu L et al (2015) Safety and efficacy of antiPCSK9 antibodies: a meta-analysis of 25 randomized, controlled trials. BMC Med 13:123

38. Gibson C, Mehran R, Bode C et al (2016) Prevention of bleeding in patients with atrial fibrillation undergoing $\mathrm{PCl}$. N Engl J Med 375:2423-2435 
39. Hokanson JE, Austin MA (1996) Plasma triglyceride level is a risk factor independent of high density cholesterol. A meta-analysis of population-based prospective studies. J Cardiovasc Risk 3:213-219
40. Wayne T (2012) A review of the role of anticoagulation in the treatment of peripheral arterial disease. Int J Angiol 21:187-189 